they run is much greater than if we operate early. When there is only tenderness and possibly slight edema it is not necessary to operate in the first twenty-four or thirty-six hours. But if this continues longer than twenty-four or thirty-six hours "conservatism" should be abandoned. The thicker and the more profuse the discharge from the middle ear the more should we favor an early operation on the mastoid. I would consider the operation indicated even when the external symptoms, such as pain, are wanting, in case the discharge from the ear does not diminish gradually in the course of some ten or twelve days under efficient treatment. since such cases are likely to become chronic.

Dr. SARGENT F. SNow, Syracuse, N. Y.-I have tried to make my position plain in this matter. I do not believe in ultraconservatism. I do not believe in taking chances in subacute or chronic cases. I do not believe in taking chances in acute eases if we have extreme symptoms. But if it seems safe I advocate free drainage and the application of ice until we can see what is going to develop. If we do not get a prompt abatement of symptoms, we should operate promptly. We must not take chances. I kept the ice on from four to six days in cases that at once began to show improvement after the free incisions and I kept the ice on to continue the improvement. If we keep the mastoid tissue at such a low temperature, as we can safely, we certainly prevent morbid activity. The point made by $\mathrm{Dr}$. Cobb about continuing conservatism too long is certainly most excellently taken. We must not continue conservatism too long. If the symptoms commence to rise again, we must at once find the cause. If there is retention of pus, we must relieve it at once. Then as to the safety of continuing the ice six or seven days; it is safe if the patient is making an uninterrupted recovery. In my experience the continuous application of cold does favor a complete resolution of the trouble. I do not advise it for any length of time. I have kept it on five or six days. In those cases where I took it off earlier I found the discharge increased and I had to enlarge the outlet or put on ice again. Then as to the influence of conservative recommendation on the general practitioner, I was afraid of that, myself, last year, and I have watched the effect of last year's paper with a great deal of interest. Since the paper has come out and the reprints have been distributed the number of practitioners who have sent me cases in the early stage has markedly increased. I have tried to emphasize the point that they must get the cases under skilled hands early. 'The diploetic mastoid is in that state in which it is unsafe to place much reliance on conservative efforts. I am very careful, in all the cases of chronic otorrhea that develop acute symptoms, to operate externally. The internal operation is applicable only when done very early.

\section{DIABETES MELLITUS;}

\section{THE LIMITATIONS OF ITS DIETETIO TREATMENT.* ARTHUR R. ELLIOTT, M.D. \\ Professor of Medicine, Post-Graduate Medical School. chICAgo.}

Over 100 years ago Rollo pointed out the supreme importance of diet in diabetes, and demonstrated that by restriction of the carbohydrate principles of food sugar could be made to disappear from the urine and a general improvement in the patient's nutrition result. In elaboration of this principle, Bouchardat laid down in their minutest details the rules of the dietetic regimen, and ever since, and until a very recent date, discussion has only beer on points of minor importance, such as the eligibility of certain foods or beverages for introduction into the various dietaries, strict or moderate. This, our most valuable means of com-

* Read at the Fifty-fourth Annual Session of the American Medical Association, in the Section on Materia Medica, Pharmacy and Therapeutics, and approved for publication by the Executive and Therapeutics, and approved for publication by the Executive
Committee: Drs. S. Solis-Cohen, George F. Butler and N. S. Davis, Jr. bating the diabetic dystrophy, was conceived in empiricism, and, until comparatively recent times, was practiced empirically, the only guide being the results obtained-the fluctuations of the glycosuria and the state of the patient's general well-being. It may be said that these indications, to a large extent, still govern our procedure, but, thanks to the work of Von Noorden, Rubner, Hutchinson and Atwater, we are now able to base our dietetic prescriptions on a physiologic foundation. The scientific justification of the dietetic treatment of diabetes may be said to be established beyond question, and the details of procedure have been well elaborated; still, to the profession at large, much is wanting in a proper understanding of its principles, and more especially its limitations.

I think it may, without prejudice, be maintained that we have not yet reached the point where we may hope, by means of any at present known remedy or combination of methods, to cure the disease. The diabetic dystrophy is too deep-seated and involves too intimately and seriously the intra-organic nutritive processes for us to hope to correct the perversion by the exhibition of drugs, or to in any way effect more than palliative results.

One result of this symptomatic treatment, to which our disappointment in attempts at specific medication has forced us, is that we have come to attach too much importance to the glycosuria and, forgetful of the fact that this is but one, and by no means the most important, manifestation of the disease, we have bent our energies toward suppressing the excretion of sugar, without full regard for the welfare of the patient in other respects. It is absolutely necessary at the outset to realize that the glycosuria per se is capable of little harm; that it is the systemic condition of which glycosuria is but the outward sign that is the threatening element, and that it is to the general nutritive state we must look for the indications which are to guide us in our treatment, and not to the amount of sugar in the urine.

It is not my wish to depreciate the value of controlling the glycosuria, but rather to emphasize the importance of looking farther for results than in the urine.

Removal of the sugar from the urine, unfortunately, does not mean cure of the disease, otherwise we would all have many recoveries to our credit. What is required for cure is a restoration of the assimilative power and improvement in general strength and well-being, and in proportion as these are brought about, we may know that we are succeeding in our treatment.

However authorities may differ regarding the pathogenesis of diabetes, the chemistry of the perversion is coming more clearly into view, and its harmful influence on systemic nutrition is better understood. As with all other nutritive diseases, we have as the essential feature of the diabetic state a hematic dyscrasia, characterized by an excess of glucose and the presence in the blood of various toxic bodies, the outcome of excessive and abnormal proteid metabolism. These factors are potent influences in bringing about deranged tissue states and are probably supplemented in that direction by defective nervous action, always a more or less prominent attendant on diabetes. These influences do not prevail to an equal degree in all cases of the disease, different cases presenting great divergence in intensity and rapidity of progress. The laboratory student would have us regard glycosuria as but syndromic, the mildest differing not in kind but merely in degree from the 
severest form. The clinician, on the contrary, divides his cases into two distinct classes, mild and severe, recognizing the difference between a slight controllable glycosuria with the patient but mildly ill, and the intractable and rapidly progressive disease with its invariably fatal termination. This broad clinical division, although somewhat arbitrary and lacking in specification, has become established by custom and is universally recognized by elinicians. The mild type of diabetes may be defined as an impairment of the power of the organism for assimilating the carbohydrate principles of food, so that hyperglycemia results and sugar appears in the urine. The various symptoms encountered depend for their origin on the presence of sugar in pathologic amounts in the blood. When the glycosuria is controlled by reduction of ingested carbohydrates, more or less prompt subsidence of all symptoms ensues in this form of diabetes.

A striking contrast to this ready control is presented by the severe form of diabetes, which undergoes comparatively little abatement in severity, even after complete withdrawal of carbohydrates from the diet, sugar still appearing in the urine, showing that the sugarsplitting function of the cells is so gravely impaired that the carbohydrate moiety of the proteid molecule can not be utilized in the economy. Progressive emaciation, polyphagia and a gradually deepening toxemia characterize this form of the disease, which presents such varied and marked contrasts to the mild type as to apparently stamp it as an entirely different pathologic process.

In the severe grades of diabetes it is generally accepted that the sugar is derived from the systemic albumin as well as from the carbohydrates of the food, whereas in the light form it comes entirely from the latter source. From an etiologic point of view, the dietetic treatment should, in many respects, be different in the two forms. In the severe all that can be accomplished by the antidiabetic diet is some reduction in the amount of circulating sugar. We can not hope to suppress the glycosuria or control the dystrophy. The utmost we can accomplish by diet is to control somewhat the glycemia and toxemia, and thus, by establishing within the body a closer approach to normal, haply effect some augmentation of strength and preservation of body albumin. In the mild form of the disease, which is an affair of starch malassimilation, to control the glycosuria by adaptation of the diet is only a rational procedure, and can not be otherwise than right. The passage of sugar that can be controlled by diet means the infliction of unnecessary harm on the tissues, and this stands in proportion to the amount of sugar that escapes combustion and is carried off by the urine.

The work of physiologic chemists shows that the diabetic converts just as much potential energy into kinetic force as the healthy individual, there being no difference in this respect between them. The diabetic is handicapped in a nutritive way, however, because of the great loss of sugar, a valuable heat and energy-producing material, by the urine, a loss which must be compensated by increased destruction of body tissues. The destruction of albumin is in this manner greatly increased, and as a result we have much augmented elimination of nitrogen and the progressive loss of weight and strength, which is so noticeable a feature of diabetes. In examples of the severe grade of diabetes there usually exists along with the breaking down of body albumin a collateral formation of organic toxins of acid character, which in their turn complicate the nutritive problem by a disturbing effect on cell protoplasm. It is this tissue waste and its attending toxemia which constitute the real danger in diabetes. Were it not for this, glycosuria would be nothing more than a disagreeable symptom with no immediate dangers, but merely remote and somewhat uncertain secondary effects.

Preservation of body albumin, under all circumstances, must constitute the standard which is to guide us in our regulation of the diet, and the endeavor must be to not only maintain the strength, but, as far as possible, add to the store of bodily energy. When viewed in this light, the body weight becomes the criterion of our success, and not the amount of sugar in the urine.

Some diminution of bodily fat is an inevitable attendant on any restriction of the diet in diabetes, and this may not be wholly undesirable in obese subjects, but it can not be allowed to proceed beyond a certain limit, even in these cases, without detriment to the general health. According to Von Noorden, in order to assure the preservation of body albumin, an amount of food adapted in accordance with general physiologic laws to the needs of the economy is necessary. If the amount sinks below these needs, that is to say, below the output for the time being of the organism, the deficit must be met by a levy, not only on the fats, but also on the albumin of the body.

By reference to Von Noorden's tables we find that a man taking moderate exereise consumes nutritive material to the value of 3.5 calories per kilogram a day. In the case of a man of 70 kilograms $(154 \mathrm{lbs}$.), the average of daily consumption would be represented by about 2,500 calories. The diet must be regulated so as to provide nutritive material to cover this total.

It has been estimated that in health man obtains from 40 to 50 per cent. of the total number of nutritive calories from the carbohydrate principles of food, the remainder being about equally divided betwen the fats and the proteids. In the diabetic state the system is not only deprived to a large extent of the immense nutritive benefit of the carbohydrates, but, as Pavy has pointed out, the effect of this class of food is diametrically opposite to its influence in the healthy state, for instead of. contributing to the increase or maintenance of weight, it leads to decrease in weight, through stimulating waste and inducing a wrong state of the system by the abnormal presence of sugar in transit in the blood. Some substitutes must, therefore, be found to take the place of the carbohydrates, and to accomplish this one has to choose either proteids or fats. The net calorie value of various food classes has been estimated by Kleen as being for proteids, 3.2 cal.; fats, 8.4 cal., and carbohydrates, 3.8 cal. in healthy subjects, and usually as much in diabetes, minus, of course, the loss by glycosuria in the latter case.

Our ideas as to the relative value of food constituents as energy producers have undergone considerable change in the light of recent physiologic observations. It was formerly believed that proteids were the principal source of bodily energy, whereas carbohydrates and fats contributed chiefly as sources of heat. It is now known that carbohydrates and fats, as well as proteids, supply energy to the body, and that, moreover, it is a matter of indifference, so far as the ultimate result is concerned, which food is supplied to the organism, provided it be given in amount proportionate to its dynamic equiva- 
lent. Heat is a secondary product, the result of cellular activity.

So far as these deductions carry us, the solution of the nutritive problem in diabetes would seem to consist simply of a proportionate increase in the amount of proteids and fats of the food, so as to meet the calorie demands of the organism. The necessity which we have to face, however, is not merely one of substitution for carbohydrates, but a multitude of difficulties complicate the problem. Some means must be devised to terminate the abnormal albumin breaking down, which is so frequently a result of the constitutional vice. Moreover, the digestive welfare of the patient must be duly taken into account, otherwise anorexia, disgust and dyspepsia will vitiate the good effects of our endeavors.

Proteids are the only food elements capable of repairing and building tissue and at the same time producing their quota of energy and heat. It would seem, therefore, that proteids are ideally qualified to act as the mainstay of the diabetic. Certain objections to the excessive use of meats and albuminous foods in the diabetic dietary must be given due consideration. Not only are albuminous foods of themselves an insufficient source of energy for the permanent maintenance of the body, but in the severe form of the disease proteids are known to add to the glycemia by means of the carbohrdrate, which is an integral part of the proteid molecule. On this account many cases of this form of the malady are found to do badly on an animal diet. Proteids, moreover, have the effect of stimulating nitrogenous metabolism, and in the excessive destruction of albumin, acetone and other acid toxins are formed which are most prejudicial to the patient's nutrition, and strongly predispose to the development of coma. A less important but still valid objection is that bacterial putrefactive changes of the proteids in the intestines are apt to add materially to the toxemia. Proteids can not be said, therefore, to be conservors of the body tissues in diabetes, but, on the contrary, may, by stimulating nitrogenous waste and increasing the toxemia, prove to have a directly opposite effect. What is needed is true conservation of the tissue albumins, and to accomplish this we must have recourse largely to carbohydrates and fats.

Fat is a compact source of energy, yielding, as we have seen, more than twice as many calories as proteids. It possesses the adrantage of not being available as a source of sugar in the economy, as proteids are, and consequently can not add to the hyperglycemia or glycosuria in any stage of diabetes. An additional advantage possessed by fats is that they can, to a considerable extent, fulfill the function of carbohydrates as albuminsparing bodies, and in this manner they aid materially in the preservation of weight and tissue.

Certain obstacles to the employment of fats in large quantities in the diet exist. They possess a lower percentage of absorption than either of the other two food classes, are more difficult of digestion and less palatable, being apt soon to disgust the taste, so that their availability becomes greatly restricted. For these reasons, notwithstanding their high calorie value, fats can not be ingested in sufficient quantity to cover the expenses of the economy. They do, however, contribute very materially thereto, and richness in fats may be said to be the leading characteristic of the diabetic diet. They are made available to the patient through the employment of various expedients, chiefly by means of the simultaneous use of carbohydrates and alcohol, for it has been found by experience that their palatability and digestibility are greatly enhanced by this association. Fortunately, all diabeties utilize some portion of ingested carbohydrates, and the calories thus gained contribute better than any other to the protection of the systemic proteids. It is, therefore, never necessary to entirely exclude from the diet this class of foods, the extent of their allowance being a matter of the patient's capacity for assimilating them and the form in which they are permitted. The permanent exclusion of carbohydrates from the food can not be effected, because without them, no matter how careful our arrangement of the dietary may be, the supply of available calories is never sufficient for the systemic needs, excessive tissue breaking down resulting to supply the deficiency, and emaciation and organic toxemia follow.

Authorities are in general accord in condemning the attempt to enforce the absolute non-saccharin diet, except perhaps for a brief period to accomplish some special result. This rule holds good in all forms of the disease. In the mild forms of diabetes, some power of starch assimilation is invariably retained, and to withhold carbohydrates entirely is to deprive the patient unnecessarily of a valuable source of energy. In the severe forms of the disease, not only do carbohydrates entirely fail of assimilation, but at the same time the systemic powers are unable to utilize the carbohydrate constituent of the albumin molecule, which acts on the blood and urine identically as does grape sugar derived from other sources. It becomes apparent, therefore, that too close restriction will avail nothing and merely result in jeopardizing the systemic tissues. As a matter of fact, it becomes as necessary, in the severe stage of the disease, to restrict the nitrogenous exchange as to limit the ingestion of carbohydrates, and in the presence of acid toxemia it is advisable to make an attempt to spare the systemic albumin which is being sacrificed, by free introduction of carbohydrates. It is to be remembered in serere diabetes that it is better to temporize with a glycosuria on a mixed diet than to force an autophagy by overstrictness, for we may fail utterly to subsequently cope with the dystrophy, which has thus received a fillip through our zeal. The weight of authority is unequivocally opposed to a too rigid nitrogenous regimen in all forms of diabetes, but especially in the severe form, it having been proved that acetone and acid toxins result from such a measure. Coma has been precipitated by the sudden institution of a strict non-starchy diet.

It becomes apparent from the foregoing considerations that the course to be pursued in the dietetic treatment of diabetes is, in the amenable stages of the discase, to allow the patient as liberal an allowance of carbohydrates as the patient can assimilate, and in the severe stages as much as is found necessary to hold in check the dystrophic advance, bearing in mind the important fact that carbohydrates only act as albumin-sparing bodies when their ingestion is followed by at least partial assimilation. At the same time every artifice must be employed to introduce the largest amount of fat that the paticnt can take. If this method is pursued it does not become necessary to restrict the nitrogenous elements of food, for by the judicious introduction of carbohydrates and fats little necessity exists for excessive devotion to any one class of foods, and seldom is the patient led into overindulgence in animal foods. The point is frequently made that it is as necessary to limit the quantity as it is the quality of the foods in diabetes. It seems to the writer an unnecessary cruelty to limit the 
amount of available foods to these patients, for the bulimia is the outcry of starved tissues, deprived of the food values necessary for their preservation, and to meet this tissue hunger by further starvation seems both cruel and unscientific. A better solution of the difficulty is reached by aljusting the diet, as far as possible, so as to provide sufficient food calories for the systemic needs in easily available forms, such as carbohydrates, fats and alcohol, and when this is successfully accomplished the excessive craving for food disappears.

Some argument exists as to the propriety of suddenly instituting a strict non-starchy diet, even for temporary experimental purposes, to determine the patient's assimilative powers. In decidedly toxic cases, experience has proved that an increase in the acetone and acid toxins is inseparable from the strict diet, and the liability to coma is greatly increased by such a measure. The question of the extent of our restriction seems to be one entirely of the phase of the disease. The general rule may be given that if on a mixed diet the patient's urine does not yield the ferric chlorid reaction one may without danger restrict the carbohydrates. If, on the contrary, the ferric chlorid reaction be present it would be a great mistake to attempt the strict or absolute, diet. In such cases there is no physiologic warrant for persisting with diet in the hope of removing the glycosuria. In the most favorable cases of mild diabetes, the absolute diet can not be followed for periods of longer than a few weeks or months. It will generally be found that patients who are fat and not nervous and who have good direstions will bear better the strict diet. Instead of fol!owing a blind routine, we must individualize as much as possible and treat each case, so far as indications will lead us, on its own merits. The advantages to be gained by dieting in diabetes do not alone consist in the control of the hyperglycemia and its effects, but experience has proved the important fact that patients who have, for a certain time, been on a diet containing no carbohydrate often acquire a tolerance for these elements and excrete much less sugar after a return to carbohydrates than they did before. The fact has been especially emphasized by Von Noorden, Naunyn, Pavy and Weintraud that the sugar-consuming function of the body is spared by the temporary withdrawal of carbohydrates, and is thus given the opportunity for some recovery and restoration. We avail ourselves in this manner of the important therapeutic principle of rest in subduing functional disturbance. It is impossible, however, to predict an improvement in assimilative capacity after dieting. The reverse may take place. Magnus Levy reports four cases in which prolonged withdrawal of carbohydrates had developed a reduced tolerance for this class of food.

It will be found desirable to place cases on the strict diet for periods of three or four weeks, once or more each year, so as to afford relief to the eliminating organs and rest to the assimilative functions. Beyond this, experience has taught us that even if we exceed somewhat the tolerance for carbohydrates, no great harm is to be feared, since it is not the slight but the excessive glutting of the system with sugar that we must avoid.

103 State Street.

\section{DISCUSSION.}

Dr. Henry Beates, Jr., Philadelphia--If we could only impress on every member of the profession the necessity for demanding elaboration of the so-called fundamental sciences included in the medical curriculum, much would be done to solve, as has been done by the reader of this paper, the complex problems in therapeusis. Experience has taught me that that physiologic teaching prevailing concerning the three types of food is either imperfect or frequently slighted and is commonly absolutely erroneous. Only a small percentage of the profession has a proper conception of these things, and more diabetics have been prematurely brought to their graves because of the pernicious dietetic treatment prescribed than would have been the case had they been left alone. As Dr. Cohen remarked a few moments ago, "What is the dose of anything? Enough." That physician who will cultivate the skill to give enough and only enough of each of the three types of food in treating diabetes mellitus will score that success which it is possible only for scientific medicine to achieve. The paper has, therefore, contributed largely to the knowledge of the scientific treatment of diabetes mellitus, and is an illustration of the need for proper teaching and for the elaboration of the applied phases of the not yet sufficiently appreciated fundamental sciences of chemistry and physiology.

DR. A. C. Croftan, Chicago-There is great confusion to-day in the mind of the average physician in regard to the question of food and food values. Our knowledge of the fate of foods is still in a more or less rudimentary state; we have only gotten to the point where we consider, on the one hand, the ingested food, and on the other the eliminatory products, so far understanding without the intermediary of food dissimilation. Thirty or forty years ago when a case presented sugar in the urine it was said that sugar must be eliminated from the diet. This recommendation was based on the belief that the food-sugar was the only source of the urinary sugar. Nowadays we know that sugar is formed from the catabolism of fats and albumins, and that a certain proportion of carbohydrate is always required to maintain full nutrition. If sugar is completely excluded from the diet the organism is simply forced to manufacture it from the albumins and fats of its proper tissues. Diabetics should therefore have some carbohydrate, but how much is the great question. I think the solution of this exceedingly difficult problem is to under take to feed the patients quantitatively, i. e., to take each case individually and to show the ingestion and excretion of sugar quantitatively, and to arrange the diet accordingly. The following has been my habit: First I deprive the patient of all carbohydrates for a short time to determine the sugar excretion, and then slowly, by weight, increase the amount of sugar until I get a small increase in the excretion of sugar. I keep the patient at this point, and do not try to get rid of all the sugar. I figure out that the calorie value of the total food, and allow, on the above basis, as liberal diet of carbohydrates as possible. A point which $I$ think is most pernicious in practice to-day is to content ourselves with a purely qualitative regulation of the diet. We must use our tables, heat values; we are as little justified in guessing here as anywhere else. In one thing I do not agree with the essayist: that is that the weight-test should supplant the sugar-test in diabetes; for if we gauge the results of our treatment of these cases from fluctuation in their weight we may be misled. There are cases in which, as we might express it, the sugar is not excreted in the urine as dextrose, but is converted into fat and deposited in the tissues as fat. These patients gain in weight, but they are suffering from diabetes as much as if there were abundant glycosuria with loss of weight, and the diet should be regulated accordingly. The matter can be regulated with mathematical precision and we should not be willing to incur the risk of underfeeding our patient; that is an error that is committed in a great majority of the cases submitting to a strict régime. Many diabetics and nephritics do not feel very sick, nor do they actually begin to fail, until they consult a physician and are promptly placed on a routine diet that slowly but unerringly starves them to death and robs them of that little reserve of resisting power they may possess.

Dr. O. 'T. Osborne, New Haven, Conn.-T approve every item in the paper, and $I$ agree with Dr. Beates that a large number of diabetics live along very nicely until they are examined for life insurance and glycosuria is discovered. They then seek 
a physician and at once, generally, begin to go downhill. In other words, the diabetic treatment of diabetes mellitus, as such, is vicious. I believe every patient should have his diet modified for diagnostic purposes according to whether he has a dietetic glycosuria or true diabetes mellitus, but the carbohydrates should not be entirely remored from his diet unless examination of the urine shows diacetic acid and ammonia to be absent. Again, a diabetic from whom the carbohydrates have been entirely removed will burn his own tissues, and the forced metabolism through which his organs are compelled to go in order to form the sugar which lie will surely excrete from the proteids that he takes is certainly detrimental. If we could say just what diabetes is we might better treat the condition. Many cases we know to be due to disease of the pancreas, and perhaps it is always due to disturbed secretion of this gland. We are now ready to state that there can be an oversecretion and an undersecretion of a ductless gland. I believe, also, there can be disturbed secretion, so that the chemical relationship of the secretion to the normal secretion may vary greatly. I think this is true of exophthalmic goiter, and accounts for the varied results from thyroid treatment. It is interesting to note that patients with exophthalmic goiter often develop diabetes, and sometimes glycosuria is produced by overfeeding of thyroid extract. It has been shown that suprarenal secretion has something to do with sugar production. I am already on record as reporting a case of diabetes in a boy to whom I administered the various internal secretions, and found that thyroid feeding was the worst thing I could give him. Feeding suprarenal tablets reduced the sugar more than any other treatment, and the boy got along well for a year. At the end of that time, for control purposes, I stopped the suprarenal for two weeks, at the end of which time he developed coma and died in three days.

Dr. W. J. Robinson, New York-The paper shows our present position in the treatment of diabetes. What has been said has been limited to the diet, and it has not been very complimentary to the physician. One patient who came under my observation was placed on the orthodox diet; he was constantly going downhill and becoming exhausted. Finally, feeling sure that he was going to die, he threw off all restrictions, and ate and drank everything, and he practically got well; of course, he believes that all physicians are humbugs. The essay shows what progress we have made in the past century, but, as a matter of fact, even fifty years ago there were physicians who claimed that restriction of the carbohydrates was irrational. Last year Dr. Mosse read a paper on the use of potatoes in diabetes and reported excellent results. Our ideas about diet in diabetes have been radically wrong, and it is our duty to scatter the knowledge as rapidly as possible, so that patients may not be hastened to their death by a too strict and irrational régime.

Dr. W. B. HILL, Milwaukee-I get the best results from a general diet, watching with the greatest care the intestinal tract, keeping it free from irritation and in the best possible condition. I know two men who have been eliminating sugar for a great many years; one has so little faith in physicians that he will not diet himself, but eats and drinks freely, and is a big, robust fellow; the other restricts himself only in the matter of drinking whisky, and drinks nothing but Seotch whisky. Both eases are doing well, and in the latter ease the sugar is becoming less.

Dr. E. T. Shelley, Atchison, Kan.-1 have had as a patient since about the middle of January an old woman whose family was startled one day by finding her wandering and unable to express her wishes. I was ealled and, suspecting diabetes, examined her urine and found it highly loaded. I put her on an antidiabetic diet and prescribed tonics. In five weeks the sugar had disappeared, and there have been no signs since that time. About two weeks ago I allowed her to eat anything she pleased, and up to the time I left there was no sugar, and she seemed perfectly well. I feel pretty sure it is not necessary to cling too rigidly to the old methods.

Dr. H. A. Moody, Mobile, Ala.-Sometines I have been impressed with the fact that cases discovered in the later years of life had been in existence for a long time before the symptoms manifested themselves sufficiently to attract attention. One case was diagnosed on account of the complete anesthesia in the right leg, the patient dislocating the little toe while pulling on a stocking, without feeling any pain. Although persuaded that there was little in the limitation of diet, I followed this plan and made every effort to keep the intestinal tract antiseptic as far as possible. The patient is getting along nicely at present, ten or more years since the time spoken of. I believe that to keep the intestinal tract in as good a condition as possible is very important. I believe many of the unfortunate symptoms which are seen in diabetics are the result of auto-intoxication. By the use of intestinal anti. septics or deodorizers and by limiting to a very moderate extent the starches and sugars of diet I usually have great hope that the patient will live until taken off by some other cause. When the diabetic condition manifests itself before the age of puberty, however, I am hopeless. I have never, in all ny experience, seen a satisfactory outcome in such a case.

Dr. W. B. Hill, Milwaukee-Some years ago $I$ saw a report from a pathologist who said that in a large number of cases dying from diabetes he had found intestinal ulceration. I would like to ask if investigation has been carried any further on this line, and what has been found.

DR. Solomon Solis-Coren, Philadelphia-There is a neces. sity for dietetic regulation in the treatment of diabetics, but that regulation is to be wisely limited, and the title of the paper is well chosen to express that thought. There is no question of our ignorance of the essential metabolic disturbance underlying diabetes. Attention must also be riveted on the points brought out by Dr. Moody-the difference of diabetes in the aged and the young, in the lean and the obese, glycosuria without diabetes, and also a mild disease simulating diabetes, but without very marked glycosuria. Diet is to be chosen and regulated quantitatively and qualitatively in accordance with at least these four varying conditions. Moreover, we must take into account the glycosuria and the diabetes of the gouty or lithemic. Just before leaving Philadelphia I saw an old gentleman 86 years of age who has been under my care for fifteen years, and who has had polyuria without sugar, and without albumin or casts in notable amount. His sister, about 62 years of age, has been under my care for the same length of time for diabetes mellitus. They come of a long-lived, gouty and diabetic family. This old gentleman tried to cut his toenails; the knife slipped and he wounded his toe. An area of gangrene developed. I examined the patient's urine, which I had been doing once a month for fifteen years, and found sugar, this developing apparently at the same time as the gangrene. The question arises whether or not this was a case of diabetes from the first with the strong family history. Dr. Thos. G. Morton operated on the toe successfully. The patient is now practically well, but still passes sugar. The point as to the diet is this: the patient is an inordinate candy-eater; probably for 85 of his 86 years he has consumed large quantities of this sweet stuff. Dr. Morton, whose experience with diabetic gangrene has been very large, advised against interfering with this diet. On the other band, I may cite the sister of this man; her glycosuria occasionally disappears and she feels very comfortable. When she goes back to carbohydrate diet the glycosuria reappears, and with it discomfort. Here we have two cases in blood-relatives, one doing thoroughly well on a large consumption of sugar, the other doing badly on the consumption of a small amount of carbohydrates.

Dr. Geo. W. Webster, Chicago-I am sure all of us occasionally have had cases following typhoid fever or infectious diseases where the patient will suddenly, without apparent cause, begin to show rapid emaciation, rapid loss of strength and weight, impairment of general health without a rise of temperature, and the general nutrition will suffer. This may occur in patients whose urine has been examined frequently, as in hospitals, and suddenly a little sugar will appear in the urine, and the case goes on rapidly to a fatal termination. My own notion is that they are not diabetic cases, as we use 
that term to cover a large series of cases, but that they are cascs of acute pancreatitis, and that we delude ourselves by calling them diabetes. Cases dying of "diabetes" do not all have diabetes, but some have pancreatitis. Within the last year or two I saw a young man who, within three months after an attack of typhoid fever and when well enough to travel, when fifteen hundred miles from home, was comparatively suddenly seized with this sudden loss of weight and strength and the appearance of sugar in the urine, and $I$ said it was a case of acute pancreatitis. The patient died, but no autopsy was held.

DR. W. W. Tompkins, Charleston, W. Va,-In West Virginia I have frequently asked older physicians about diabetes in the negro. Although possibly one-fourth of our population is of the negro race, and although they have typhoid fever and the other serious diseases from which we suffer, I have never seen a case of diabetes in them, nor could $I$ find another practitioner who had done so. Before the war insanity was unknown among the negroes, but since that time it is not uncommon. Has Dr. Elliott ever personally treated diabetes in the negro?

DR. A. R. Llliotr-I have never seen a case of diabetes in the negro. Dr. Tyson a few years ago stated that he had never seen a case in the negro. It is extremely rare in the negro, but conmon among other colored races, as the East Indians. I agree with Dr. Webster that glycosuria of a pancreatic type may be brought about as a result of typhoid fever. It seems to me reasonable to suppose that inasmuch as the infection may spread from below up the common bile duct to the gall bladder and liver, we may also have an infection spreading over to the pancreas with resulting inflammatory changes in that organ. In regard to the further investigation of the occurrence of ulcers in the bowel in diabetics, I have no information. It is well known that colitis is a very frequent complication in diabetes, produced no doubt by the irritation of hardened fecal matter in the lower bowel. For this reason it has always seemed to me one of the most important therapeutic measures to keep the lower bowel well cleared of fecal matter by enemata to prevent any tendency to coprostasis. I agree with Dr. Beates that many patients are overdieted, and sometimes rue their consultation with physicians. It is not uncommon to hear an old diabetic regret that he ever consulted a physician because, whereas he was in good health before that time, he has suffered ever since in the attempt to combat the disease by dieting. That is unquestionably due to a misconception of the dietetic problem, and the patient is unwarrantably condemned to a strict diet. I believe the attention of the profession is focused entirely too much on the glycosuria, and my general statement that the weighing scales are a better criterion for success in our practice than the presence of glycosuria $I$ believe is true. I am glad to accede the point made by Dr. Croftan that this statement is capable of exception. Since I wrote this paper a case has come to my attention to refute my own statement. In a young girl who has been diabetic for a year and a half, the disease has assumed a vicious toxic form, and diacetic acid and acetone are present in the urine; yet she is gaining in weight. She is very toxic, and her breath smells of acetone.

\section{FMPYEMA OF THE ANTRUM.*}

\section{O. N. HEISE, M.D., D.D.S. CINCINNATI.}

In looking over the literature of the above-named subject I have again and again been impressed by the few references to the difference between a cystic empyema, so called, and a true empyema, the one being due to the encroachment of a dentinal or alveolar cyst to the antrum, the other a true infection of the antrum either from dental or nasal origin.

- Read at the Fifty-fourth Annual Session of the American Medical Association, in the Section on Stomatology, and approved Medical Association, in the Section on Stomatology, and approved for publication by the Executive Com
In an article on empyema of the antrum in one of our leading dental journals not long ago I noticed a statement as follows:

Within the last few years a comparatively new affection, frequently confounded with antral empyema, has appeared. Dentigerous eysts arise as you know about the tooth roots and slowly dilate the tissue at the root of the tooth.

I quote this principally to show that affections of the teeth and alveolar process in relation to antral troubles do not receive the attention they deserve. If the author of that article had taken the trouble to inform himself he would have found that it was not a new affection, also that a dentigerous cyst is a different condition of affairs from that he states it to be.

These maxillary cysts, when found in the neighborhood of the molars and bicuspids can, and do, in their development, raise or push the floor of the antrum to such an extent that finally the thin intervening lamella of bone is resorbed, leaving only the periosteum and the lining mucous membrane of the antrum as a covering. I have often seen the encroachment such as to include the entire antrum, filling it completely, in its further derelopment raising both outer and inner wall, as well as the roof.

Antral cysts developing within the cavity must of necessity first completely fill it before they can produce any abnormality in the way of bulging of either wall, and can, I think, be recognized as having their origin from within, instead of having developed within the alveolar process. The facial wall, being extremely thin, owing to the resorption of the bone, leaves at times a decided defect in the wall, whereas in the dental or alveolar origin the thinness of the wall is found to be in the alveolar region or process. They are more frequent than has been supposed, not only in connection with antral lesions, but in other regions of the alveolar process; both in the upper and lower maxilla. Many an abscess has been treated with little or no success, tooth finally extracted, socket curetted, packed, etc., thinking it to be either a case of caries or necrosis; whereas, if the proper diagnosis had been made, the tooth could easily have been saved by proper treatment, especially the single-rooted teeth.

The domain of the stomatologist runs very closely into that of the rhinologist. Every now and then in the treatment of an obstinate antral suppuration we find that the trouble is not so much in the antrum as in some of the accessory cavities, draining into the antrum, making a reservoir, so to speak, of it, treating only the effect, not the true cause in such instances. This fact, and also the frequent occurrence of empyema after la grippe, has led some men to almost doulst the dental origin of antral empyema. There is no question at all in my mind that many antral cases are primarily due to infection from some accessory cavity, or other nasal disease. Nevertheless, dental causes are, and will remain, prominent etiologic factors.

The difference of opinion as to the main causation of antral empyema depends greatly on the view-point taken. Reminding one of the oriental story of the three blind men who went one day to inspect an elephant: "He is like a spear," said one who grasped the tusk; "he is like a fan," said another who felt the ear, while the third with his hand on the leg declared he was like a tree. 'They had all inspected the elephant, but, naturally, formed different ideas of his appearance. 'So it is with the etiology of antral cmpyema. Various observers form various views from various experiences, 